\title{
Mekânsal Verilerin Sıklıkla Güncellendiği Coğrafi Bilgi Sistemleri Arama İşleminde Denormalizasyon Yöntemi
}

\author{
Murat Taşyürek $^{1 *}$ \\ 1* Kayseri Üniversitesi, Mühendislik Mimarlık ve Tasarım Fakültesi, Bilgisayar Mühendisliği Bölümü, Kayseri, Türkiye, (ORCID: 0000-0001-5623-8577), \\ murattasyurek@kayseri.edu.tr
}

(2nd International Conference on Access to Recent Advances in Engineering and Digitalization (ARACONF)-10-12 March 2021)

(DOI: $10.31590 /$ ejosat.899302)

ATIF/REFERENCE: Taşyürek, M. (2021). Mekânsal Verilerin Sıklıkla Güncellendiği Coğrafi Bilgi Sistemleri Arama İşleminde Denormalizasyon Yöntemi. Avrupa Bilim ve Teknoloji Dergisi, (24), 18-23.

\begin{abstract}
$\ddot{\mathbf{O z}}$
Coğrafi Bilgi Sistemleri (CBS), nesnelere ait öznitelik bilgilerine ilaveten nesnelerin konumlarını mekânsal veri formatında toplama, saklama, düzenleme, görüntüleme, kontrol ve analiz etme gibi işlemlerin sunulduğu karar destek sistemidir. CBS, farklı disiplinleri ilgilendirmesinden dolayı ve özellikle bilişim teknolojilerinde yaşanan gelişmeler ile web ve mobil platformlarda yaygıı olarak kullanılmaktadır. Bu teknolojileri kullanan insanlar aradıkları bilgilere anında ve güncel haline ulaşmak istemekte ve buna olanak sağlayan CBS uygulamalarını kullanmayı tercih etmektedir. Bu sebepten dolayı mekânsal verilerin sıklıkla güncellendiği CBS sistemlerinde arama işlemlerinin hızlıca yapılması ve kullanıcıya güncel bilgilerinin sunulması önem arz etmektedir. CBS sisteminde ise mekânsal veriler nokta, çizgi ve poligon gibi geometri veri tiplerinden oluşur ve genellikle geometri veri tipine göre veritabanında farklı tablolarda tutulduğundan dolayı farklı tablolarda aynı anda arama işlemi zor bir problemdir. Veritabanı tasarımında, ihtiyaç olmayan özellikler ekleyerek veya özellikleri bir araya getirerek veritabanı cevap verme süresini azaltmak için yapılan işlemler denormalizasyon olarak tanımlanır. Bu çalışmada, mekânsal verilerin sıklıkla güncellendiği CBS sisteminde arama işlemlerinin hızlanması için denormalizasyon tabanlı yeni bir sistem önerilmiştir. Bu çalışmada önerilen sistemde Oracle veritabanında Kayseri Büyükşehir Belediyesine ait mekânsal veriler kullanılmıştır. Önerilen denormalizasyon tabanlı sistemde, farklı tabloda tutulan ve sıklıkla güncellenen mekânsal veriler arama işlemlerinin hızlı yapılması için genelleştirilmiş bir tabloda tutulmuştur ve veritabanı işlemleri ile bu verilerin güncelliği sağlanmıştır. Önerilen sistem gerçek veriler üzerinde normalizasyon tabanlı arama yöntemi ile karşılaştırılmıştır. Deneysel sonuçlar, önerilen denormalizasyon tabanlı sistemin normalizasyon tabanlı sisteme göre daha hızlı sonuçlar verdiğini göstermiştir.
\end{abstract}

Anahtar Kelimeler: Mekânsal veriler, Coğrafi bilgi sistemi (CBS), Genel arama, Denormalizasyon.

\section{Denormalization Method in Geographical Information Systems Search Process where Spatial Data is Frequently Updated}

\begin{abstract}
Geographic Information Systems (GIS) is a decision support system that allows operations such as collecting, storing, updating, controlling, analyzing and displaying information in spatial data format. GIS is widely used in web and mobile platforms due to its interest in different disciplines and especially due to developments in computer technology. People using these technologies want to access the information they are looking for instantly and up-to-date and prefer to use GIS applications that enable this. For this reason, in GIS systems where spatial data are frequently updated, it is important to perform the searches quickly and to provide up-to-date information to the user. In the GIS system, spatial data consist of geometry data types such as point, line and polygon, and searching in different tables at the same time is a difficult problem since they are usually kept in different tables in the database according to the
\end{abstract}

* Sorumlu Yazar: murattasyurek@kayseri.edu.tr 
geometry data type. In database design, the operations performed to speed up the reading from the database by adding unnecessary features or combining features are defined as denormalization. In this study, a new denormalization-based system is proposed to accelerate the search processes in the GIS system where spatial data are frequently updated. In the system proposed in this study, spatial data belonging to Kayseri Metropolitan Municipality was used in the Oracle database. In the proposed denormalization-based system, spatial data kept in different tables and frequently updated are kept in a generalized table for fast search operations, and these data are kept up to date with database operations. The proposed system is compared with normalization-based search method on real data. Experimental results show that the proposed denormalization-based system gives faster results than the normalization-based system

Keywords: Spatial data, Geographic information system (GIS), General search, Denormalization.

\section{Giriş}

Coğrafi Bilgi Sistemleri (CBS), nesnelere ait öznitelik bilgilerine ilaveten konumlarını mekânsal veri formatında toplama, saklama, düzenleme, görüntüleme, kontrol ve analiz etme gibi işlemlerin sunulduğu karar destek sistemidir (Tecim, 2008, Taşyürek ve ark., 2020). CBS, farklı disiplinleri ilgilendirmesinden dolayı ve özellikle bilişim teknolojilerinde yaşanan gelişmeler ile web ve mobil platformlarda yaygın olarak kullanılmaktadır (Kanlı ve ark., 2018; Taşyürek ve ark., 2021). $\mathrm{Bu}$ teknolojileri kullanan insanlar aradıkları bilgilere anında ve güncel haline ulaşmak istemekte ve buna olanak sağlayan CBS uygulamalarını kullanmayı tercih etmektedir (Ahmet ve ark., 2019). Bu sebepten dolayı mekânsal verilerin sıklıkla güncellendiği CBS sistemlerinde arama işlemlerinin hızlıca yapılması ve kullanıcıya güncel bilgilerinin sunulması önem arz etmektedir. CBS sisteminde ise mekânsal veriler nokta, çizgi ve poligon gibi geometri veri tiplerinden oluşur (Shekhar ve ark., 1999) ve genellikle geometri veri tipine göre veritabanında farklı tablolarda tutulduğundan dolayı farklı tablolarda aynı anda arama işlemi zor bir problemdir.

Veritabanı tasarımında genellikle ilişkisel veritabanı teorisi olarak adlandırılan normalizasyon işlemi kullanılır (Powell ve ark., 2006). Normalizasyon, çok fazla sayıda satır ve sütun içeren bir tabloyu tekrar eden kayıtları elimine ederek daha az satır ve sütun içeren alt tablolar oluşturma işlemidir. Fakat veritabanındaki tablo sayısı arttıkça ve bunun sonuncunda kayıt sayısı arttıkça verinin içinde arama işleminin süresi uzayacaktır. Veritabanında arama işlemini hızlandırmak için arama yapılan sütunlara indeks oluşturmak arama işleminin süresini kısaltacaktır (Beeri ve ark., 1989) fakat veriler farklı tablolarda tutulduğundan dolayı veritabanında farklı tablolarda aynı anda arama işlemi ancak görünüm (view) yapısı üzerinden olabilir ve oracle veritabanı görünüm yapısına indeks oluşturulmasına izin vermemektedir (Bello ve ark., 1998). Veritabanı tasarımında, ihtiyaç olmayan özellikler ekleyerek veya özellikleri bir araya getirerek veritabanı cevap verme süresini azaltmak için yapılan işlemler denormalizasyon olarak tanımlanır (Uzun ve ark., 2018). Literatürde klasik veritabanlarında denormalizasyon yöntemleri ile arama işlem süresinin kısaltıması konusunda yapılan çalışmalalar bulunmaktadır (Uzun ve ark., 2018; Karnitis ve ark., 2015). Bu çalışmada, mekânsal verilerin sıklıkla güncellendiği CBS sisteminde arama işlemlerinin hızlanması için denormalizasyon tabanlı yeni bir sistem önerilmiştir. $\mathrm{Bu}$ çalışmada önerilen sistemde Oracle veritabanında gerçek veri olarak Kayseri Büyükşehir Belediyesine (KBB) ait mekânsal veriler kullanılmıştır.

$\mathrm{Bu}$ çalışmanın bundan sonraki bölümlerinde denormalizasyon modeli tanıtılmış, mekânsal verilerin sıklıkla güncellendiği CBS sisteminde denormalizasyon yöntemi ile arama işlemi sunulmuş ve daha sonra sonuçlar bölümünde ise yapılan deney sonuçları ve uygulama paylaşılmıştır.

\section{Materyal ve Metot}

$\mathrm{Bu}$ çalışmada denormalizasyon işlemi verilerin sıklıkla güncellendiği CBS sistemlerininde arama işlemlerinin hızlandırılması için kullanılmıştır. $\mathrm{Bu}$ nedenle öncelikle denormalizasyon işlemi tanıtılacak ve daha sonra ise mekânsal veritabanı tablolarında hızlandırma işlemleri tartışılacaktır.

\subsection{Veritanlarında Denormalizasyon}

Denormalizasyon, bir veya daha fazla tabloya fazladan veri eklediğimiz bir veritabanı optimizasyon tekniğidir (Shankar ve ark., 2018). Veritabanı tasarımında, normalizasyon işleminde ihtiyaç duyulmayan özellikler ekleyerek veya özellikleri bir araya getirerek veritabanından okuma işlemini hızlandırma olarak da tanımlanır. Uzun vd. (Uzun ve ark., 2018) üniversite anket uygulamasının performansını artırmak için denormalizasyon işlemi uygulamış ve normalizasyon işlemine göre performans artışını göstermiştir. Pogodaev vd. (Pogodaev ve ark., 2020) denormalizasyon yapılmış veritabanlarından sorgu performansını artırmak için materyalleştirilmiş görünüm (view) tabanlı bir yöntem önermiştir. Cavique vd. (Cavique ve ark., 2019) çoklu erişim yolu sorununun neden olduğu anlamsal ve bağlantı hatalarını gidermek için ilişkisel veritabanlarında denormalizasyon kuralı oluşturma üzerine bir çalışma yapmıştır.

Denormalizasyon işlemi "önce normalize işlemini uygula, eğer performans problemi var ise denormalize işlemini uygula" felsefesi üzerine kuruludur (Shankar ve ark., 2018). Siklıkla kullanılan denormalizasyon işlemleri, birden fazla tablodan veri çekilmesi durumunda join işlemleri ile bu tablolardan bir üst tablo oluşturulması (Cavique ve ark., 2019), SQL grup fonksiyonlarının sorguyu yavaşlatması durumunda yeni bir sutun açılarak bu değerlerin önceden hesaplanıp sütuna yazılması ve birden fazla satır veya sütunun birleştirip tek bir sütun haline getirilmesi olarak siralanabilir (Date ve ark., 2019). Denormalizasyon işleminin avantajları aşağıdaki şekilde siralanabilir (Zhang ve ark., 2018):

- Daha az birleştirme (join) işlemi yapıldığı için verilerin okunması daha hızlıdır.

- Daha az tabloya sorgu çekildiğinden yazılacak sorgu cümleleri daha basittir.

Denormalizasyon işlemi veri okumayı hızlandırsa da bu işlemin dezavantajı vardır ve veritabanında sıkıntılara yol açabilir. Denormalizasyon işleminin dezavantajları aşağıdaki şekilde sıralanabilir (Hay ve ark., 2020):

- Güncelleme işlemi ve ekleme işlemi daha zordur.

- Denormalizasyon işlemi güncellemeyi ve kod yazmayi zorlaştırır. 
- Birden fazla veri oluşacağından dolayı veri tutarsızlığı oluşabilir.

- Veri boyutu büyüdükçe daha fazla depolama alanı ihtayc1 artacaktır.

$\mathrm{Bu}$ çalışmada, mekânsal verilerin sıklıkla güncellendiği CBS sisteminde arama işlemini hızlandırmak için denormalizasyon tabanlı materyalleştirilmiş görünüm yapısı oluşturulacaktır.

\section{Problem ve Çözümler}

Problem, KBB tarafından coğrafi bilgi sistemine ait mekânsal verilerinin kent bilgi sistemi web sitesinde yayınlanması ve web sitesi gene arama işleminde ortaya çıkmıştır. İlk olarak uygulamada, klasik veritabanı tasarım süreçlerinden olan normalizasyon işlemi uygulanmış ve genel arama problemine çözüm üretilmeye çalışılmıştır. Ancak, geliştirme aşamasında normalizasyon tabanlı sistemin arama işlemine çok uzun sürede cevap verdiği görülmüştür. $\mathrm{Bu}$ noktada, mekânsal verilerin sıklıkla güncellendiği coğrafi bilgi sistemlerinde arama işleminin daha hızlı yapılması için denormalizasyon tabanlı materyalleştirilmiş görüntü oluşturma işlemine gidilmiş ve arama süresinin azaltılmasına çalışılmıştır.

\subsection{Normalizasyon Tabanlı Çözüm}

Yapılan incelemeler sonucunda normalizasyon yapılacak veriler adı, türü, ilçe, mahalle adı, cadde sokak bulvar küme evler (CSBM) adı, konum bilgisi, ulusal adres veritabanı (UAVT) kodu ve dış kapı numarası olarak belirlenmiştir. Kayseri Büyükşehir sınırları içerinde bulunan ve coğrafi karşılı̆̆ olan ilçe sınırı, mahalle sınırı, cadde sokak bulvar küme evler yol bilgisi, bina yap1 bilgisi, kap1 numarası bilgisi, cami, okul, eczane, hastane ve benzin istayonları gibi coğrafi olarak karşılı̆̆ olan yerlerin CBS sisteminde mekânsal olarak tutulmasını ve değişen verilerin anlık olarak güncellenmesini planlamaktadır. Oracle veritabanında mekânsal indekslerin daha hızlı ve verimli olması için mekânsal sütunlarda tek bir veri tipinin (nokta, çizgi veya poligon) tutulması tavsiye edilir ( $\mathrm{Li}, 2010)$. Bu nedenle mekânsal veriler geometri veri tipine göre ayrıldığında ve normalizasyon işlemi sonrasında aşağıdaki şekilde tablolar oluşmuştur.

- Ilce (IlceNo, Adi, Geometri, UavtKod)

- Mahalle (MahalleNo, IlceNo, Adi, Geometri, UavtKod)

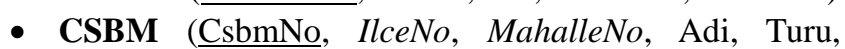

Geometri, UavtKod)

- Bina (BinaNo, IlceNo, MahalleNo, CsbmNo, Adi, Turu, Geometri, UavtKod)

- DisKapiNumarasi (DisKapiNo, BinaNo, IlceNo, MahalleNo, CsbmNo, Adi, Turu, Geometri, UavtKod)

- OnemliNoktalar (NoktaNo, IlceNo, MahalleNo, CSBMNo, BinaNo, DisKapiNo, Adi, Turu, Geometri, UavtKod)

Yukarıda tablo isimleri kalın renkli, birincil anahtar altı çizili, ikincil anahtarlar ise italik olarak gösterilmiştir. Adres alt yapısı ilçe, mahalle, CSBM, bina ve kapı olarak oluşur. İlçe sınırları poligon şeklindedir ve "Ilce" tablosunda tutulmuştur. Mahalle sınırları poligon şeklindedir ve "Mahalle" tablosunda tutulmuştur. CSBM çizgi şeklindedir ve "CSBM" tablosunda tutulmuştur. Bina verileri poligon şeklindedir ve "Bina" tablosunda tutulmuştur. Dış kapı numarası nokta şeklindedir ve "DisKapiNumarası" tablosunda tutulur. Fakat bina içerisinde olan fakat kendi başına bir bina olmayan ve önemli noktalar olarak adlandırılan (Sheha ve ark., 2006) eczane gibi önem teşkil eden konumlar OnemliNoktalar tablosunda tutulmuştur. Yapılan bu işlem ile veriler geometrik veri tipine göre farklı tablolarda tutulduğundan dolayı mekânsal indeksler oluşturulabilir ve doğal olarak mekânsal analizler hızlı bir şekilde yapılabilir. CBS programları genellikle mekânsal indeksleri kullandığından dolayı dünya genelinde yaygın olarak kullanılan ArgGIS, Geomedia ve CitySurf gibi programlar ile veri ekleme, düzenleme veya silme işlemleri hızlıca yapılacaktır.

CSB sistemini kullanan herhangi bir kullanıcı sistemde bir arama işlemi yapacağı zaman aradığı noktanın ilçe, mahalle, csbm, bina, kapı numarası veya önemli nokta olup olmadığını bilemez. Arama işleminin bütün kayıtlarda arama yapması için normalizasyon işlemleri kapsamında bütün tabloları tek bir görünümde (view) bir araya getiren bir yap1 oluşturulabilir. Bütün tablolar hepsini birleştirme (union all) komutu sayesinde birleştirildiğinde oluşacak yap1 Şekil 1'de gösterilmiştir. Normalizasyon işlemi sayesinde oluşan bu görünümde tek bir sorguda bütün arama işleminin yapılması mümkündür fakat hepsini birleştirme komutu yavaş çalıştığından dolayı veri boyutu arttıkça performans kaybı da artacaktır.

\subsection{Denormalizasyon Tabanlı Çözüm}

Oracle veritabanı yapası klasik görünüm (view) üzerinde indeks oluşturulmasına izin vermez. Normalizasyon işlemi

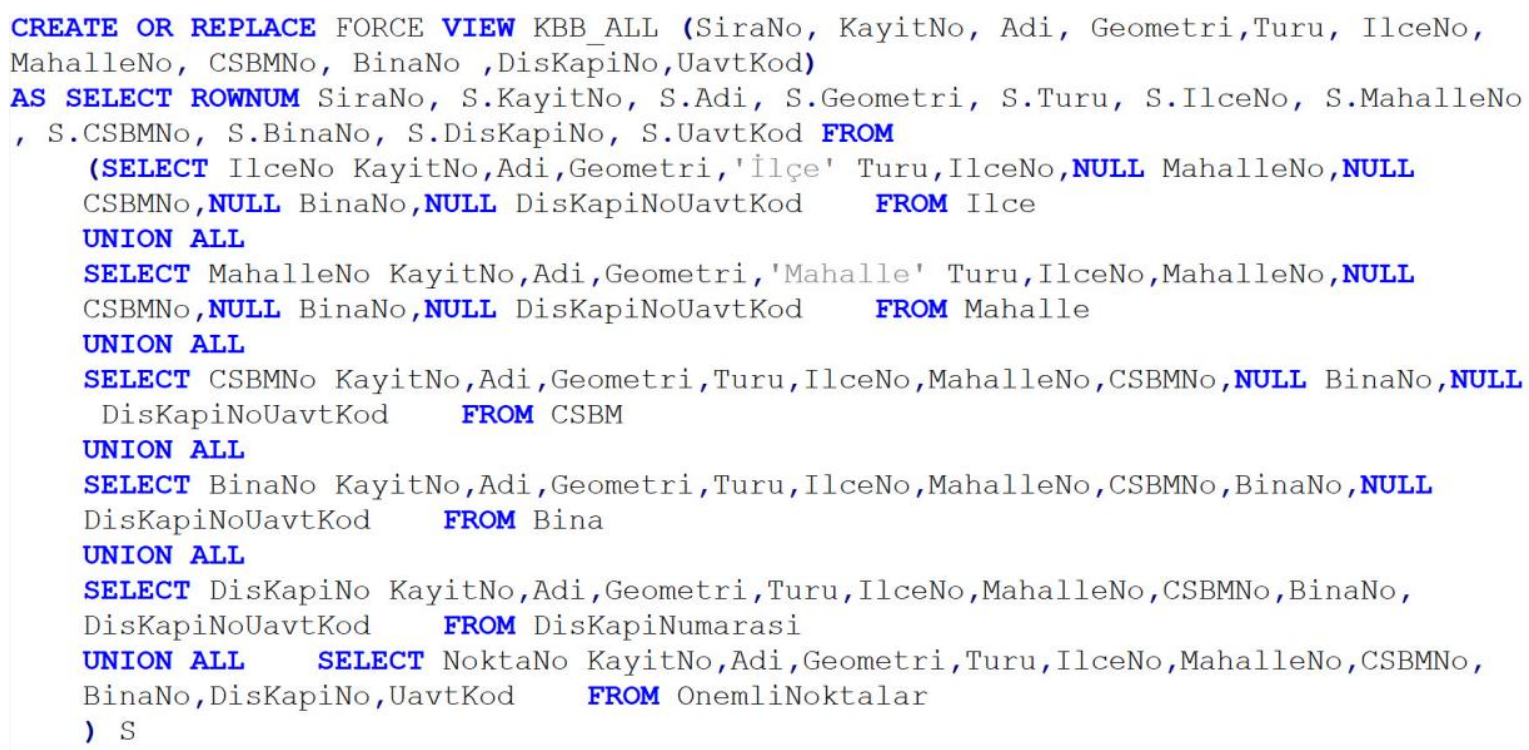


kapsamında arama işlemini tek sorguda yapmak için oluşturulan görünüme indeks oluşturulamadığından dolayı arama işlemi yavaş çalışacaktır. Denormalizasyon işlemi "önce normalize işlemini uygulama, eğer performans problemi var ise denormalize işlemini uygula" felsefesi üzerine kuruludur (Shankar ve ark., 2018). Arama işlemi için normalizasyon işlemi yapıldığından dolayı denormalizasyon işlemi yapılabilir. Denormalizasyon, veritabanı tasarımında ihtiyaç duyulmayan özellikleri ekleyerek veya özellikleri bir araya getirerek veritabanı cevap verme süresini azaltmak için yapılan işlemler olarak tanımlanır. Denormalizasyon işlemleri kapsamında arama işlemini hızlandırmak için "KBB_ALL" görünümünden materyalleştirilmiş bir görünüm oluşturulacaktır. Oracle veritabanı yapısında materyalleştirilmiş görünüm, bir sorgunun sonuçlarını içeren veritabanı nesnesi, tabla veya görünümdeki verilerin kopyasıdır veya özetidir (Yu ve ark., 2011). Şekil 2'de KBB için oluşturulan materyalleştirilmiş görünümün SQL kodu verilmiştir.

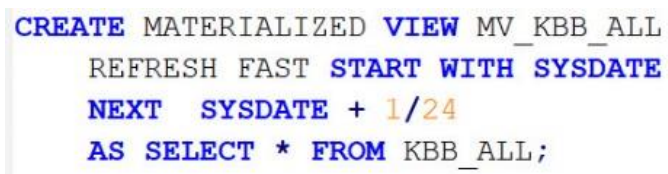

Şekil 2 Materyalleştirilmiş Görünüm

Şekil 2'de gösterilen "MV_KBB_ALL” görünümüne veri ekleme, güncelleme veya silme işlemi için ihtiyaç yoktur fakat oracle veritabanı klasik görünüme indeks oluşturulmasına izin vermediğinden dolayı arma işleminin hızlı yapılması için ihtiyaç vardır. Oluşturulan bu görünümün geometrik sütunu hariç diğer sütunlarına indeks oluşturulmuştur. KBB coğrafi bilgi sistemlerinde mekânsal veriler sıklıkla güncellenmektedir ve kullanıcılar arama işleminin hızlı olması kadar aradığı verilerin güncel olmasına dikkat etmektedir ve bu nedenle Şekil 2'de oluşturuan görünüm saatte bir $(1 / 24)$ güncellenmektedir. CBS sisteminde bir güncelleme olduğu durumda en geç bir saat içerisinde verinin güncel hali arama işlemin yansımaktadır. Burada materyalleştirilmiş görününüm yenileme sıklığ değiştirilebilir fakat aşırı sık yenileme veritabanını yoracaktır ve daha az yenileme işleminde ise kullanıcılar güncel verilere erişemeyecektir. KBB ile yapılan değerlendirmeler sonucunda ideal sürenin bir saat olduğuna karar verilmiştir.

\section{Araştırma Sonuçları ve Tartışma}

$\mathrm{Bu}$ çalışmada KBB'den alınan gerçek nesnelerin konumsal verileri kullanılmıştır. Tablo 1'de KBB'ye ait verilerin özet bilgisi gösterilmiştir. Tablo 1'de KBB'ye ait 16 adet ilçe bulunmaktadır ve bu ilçe sınırları içerisinde mekânsal olarak karşılığı olan mahalle, csbm, bina, dış kapı numarası ve önemli noktalar deneysel çalışmada kullanılmıştır.

Tablo 1. KBB Mekânsal Veriler

\begin{tabular}{l|l|l}
\hline Tablo Adı & Geometrik Veri Tipi & Kayıt Sayısı \\
\hline İlçe & Poligon & 16 \\
\hline Mahalle & Poligon & 714 \\
\hline CSBM & Çizgi & 26.543 \\
\hline Bina & Poligon & 256.681 \\
\hline DisKapiNumarasi & Nokta & 282.748 \\
\hline OnemliNoktalar & Nokta & 7.577 \\
\hline KBB_ALL & - & 574.279 \\
\hline$M V \_K B B \_A L L$ & - & 574.279 \\
\hline
\end{tabular}

Bu çalışmada gerçekleştirilen deneyler Intel Xenon E5-2660 V3 $2.30 \mathrm{GHz}$ (4 Core) $16 \mathrm{~GB}$ Ram 500 GB Sata disk özelliklerine sahip ve Windows Server 2016 sunucu işletim sistemi kurulu olan bir bilgisayar ortamında çalıştırılmıştır.

\subsection{Deneysel Sonuçlar}

Normalizasyon ve denormalizasyon tabanlı çözümlerinin sonuçları karşılaştırmak için çalıştırılan sorguların cevap verme süreleri incelenmiştir. Sorguların cevap verme süreleri saniye cinsinden incelenmiş olup, sorgu sonucunun doğru süreyi hesaplaması için her bir sorgu 20 defa çalıştırılıp ortalama cevap verme süresi alınmıştır.

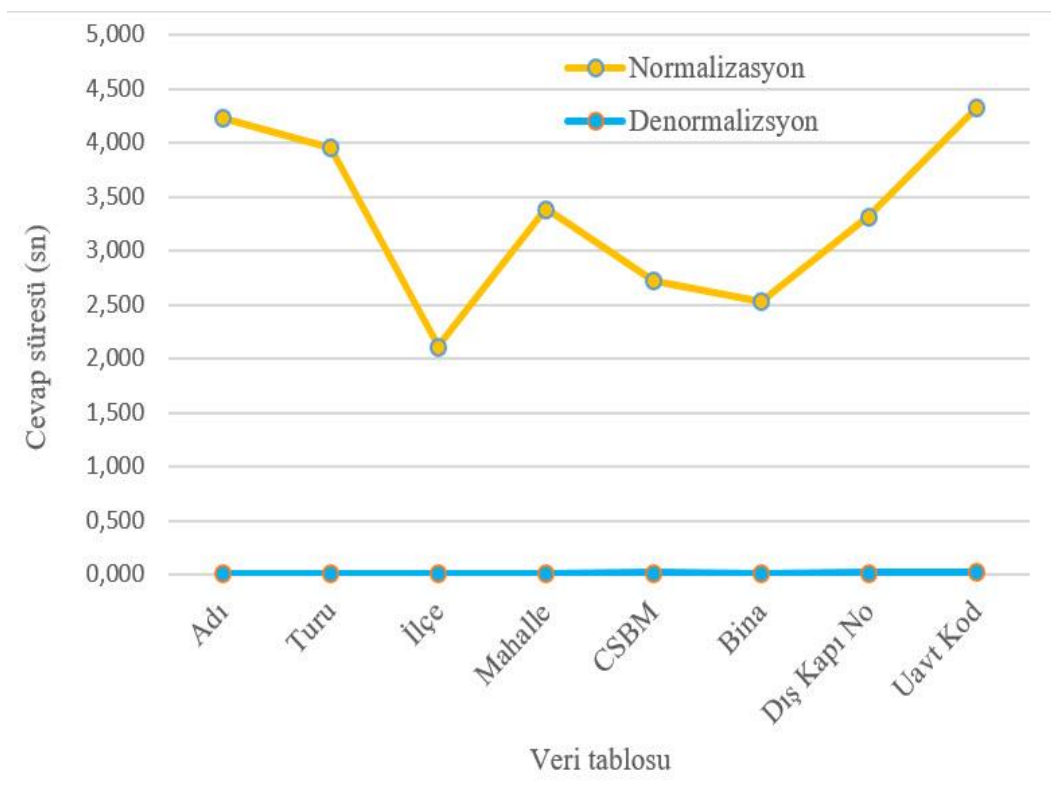

Şekil 3 Yöntemlerin Cevap Verme Süreleri 
KBB_ALL ve MV_KBB_ALL görünümünde bulunan her bir alan için sorgular ayrı ayrı çalıştırılmıştır. Normalizasyon tabanlı yaklaşım KBB_ALL görünümü kullandığından dolayı ve bu görünümde indeks eklenemediğinden dolayı cevap verme süresi daha uzun çıkmıştır. Normalizasyon ve denormalizasyon tabanlı yöntemlerin cevap verme süreleri Şekil 3'te gösterilmiştir.

Denormalizasyon tabanlı yaklaşım MV_KBB_ALL görünümünü kullanmıştır ve görünümde bulunan sütunlara indeks eklenebildiğinden dolayı sorguların cevap süreleri çok düşük çıkmıştır. Normalizasyon ve denormalizasyon tabanlı yaklaşımların cevap verme sürelerini daha iyi incelemek için cevap verme sürelerinin saniye türünden rakamsal değerleri Tablo 2'de verilmiştir. Tablo 2'de her iki yöntemin cevap verme süreleri incelendiğinde denormalizasyon tabanlı yaklaşımın normalizasyon tabanlı yaklaşıma göre en az 180 kat daha hızlı çalıştığ 1 görülmektedir.

Tablo 2. Yöntemlerin Cevap Verme Süreleri

\begin{tabular}{l|l|l}
\hline Sütün & Normalizasyon & Denormalizasyon \\
\hline$A d \imath$ & 4,232 & 0,014 \\
\hline Turu & 3,954 & 0,013 \\
\hline İçe & 2,112 & 0,009 \\
\hline Mahalle & 3,387 & 0,012 \\
\hline CSBM & 2,726 & 0,015 \\
\hline Bina & 2,532 & 0,014 \\
\hline Dış Kapı No & 3,321 & 0,016 \\
\hline Uavt Kod & 4,327 & 0,023 \\
\hline
\end{tabular}

\subsection{Kent Bilgi Sistemi Uygulaması}

Önerilen denormalizasyon tabanlı yaklaşım KBB'nin kent bilgi sistemi sayfasında kullanılmaktadır. Kent bilgi sistemi sayfasına https://cbs.kayseri.bel.tr/kayseri-kent-bilgi-sistemi adresinden erişilmektedir. Açılan sayfada çalışan arama kutucuğuna aranacak kelime yazıldığında arkama planda önerilen denormalizasyon tabanlı yaklaşım çalışmaktadır. Önerilen yöntem çok hızlı bir sürede arama işlinin sonucunu ekrana getirmekte ve kullanıcılar ekranda görmüş olduğu mekânsal veriye tıklayarak harita üzerindeki karşılığını görebilmektedir. KBB tarafından aktif olarak kullanılan denormalizasyon tabanlı uygulamanın ekran görüntüsü Şekil 4'te gösterilmiştir.

\section{Sonuç}

CBS sistemi birçok farklı disiplini ilgilendirdiğinden dolayı ve gelişen teknolojilerden dolayı yaygın olarak kullanılmaktadır. Mekânsal verilerin sıklıkla güncellendiği CBS sistemlerine aranan bilgiye hızlı bir şekilde ve güncel haline erişilmesi çok önem arzetmektedir. Bu çalışmada, mekânsal verilerin sıklıkla güncellendiği CBS sistemlerinde genel arama işleminin hızlı bir şekilde yapılması için denormalizasyon tabanlı bir yaklaşım önerilmiştir. Önerilen yöntemin sonuçları normalizasyon tabanlı yöntemin sonuçları ile karşılaştırılmıştır. Deneysel sonuçlar önerilen yaklaşımın normalizasyon tabanlı yaklaşıma göre çok daha iyi sonuçlar ürettiğini göstermiştir.

\section{Teşekkür}

$\mathrm{Bu}$ çalışma kapsamında kullanılan gerçek nesnelere ait sık güncellenen mekânsal verileri paylaştığı için Kayseri Büyükşehir Belediyesi'ne teşekkür ederiz.

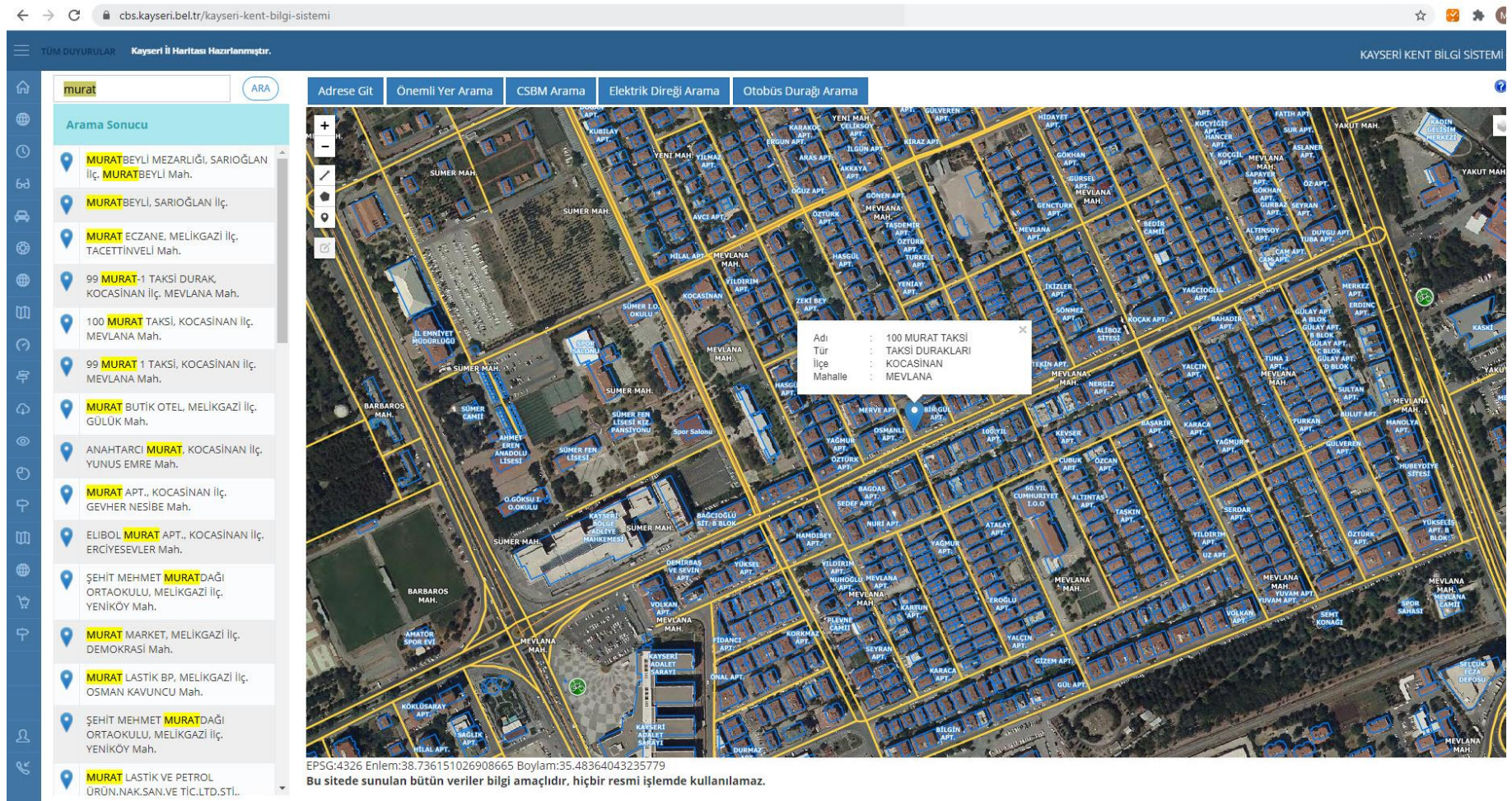

Şekil 4 KBB Kent Bilgi Sistemi 


\section{Kaynakça}

Ahmet, U., Özmen, H. B., \& Uyguçgil, H. (2019). Coğrafi Bilgi Sistemleri A $\breve{g}$ Analizinde Anlı Dinamik Sorgulama Simülasyonu. Afyon Kocatepe Üniversitesi Fen ve Mühendislik Bilimleri Dergisi, 19(3), 743-749.

Beeri, C., Bernstein, P. A., \& Goodman, N. (1989). A sophisticate's introduction to database normalization theory. In Readings in Artificial Intelligence and Databases (pp. 468-479). Morgan Kaufmann.

Bello, R. G., Dias, K., Downing, A., Feenan, J., Finnerty, J., Norcott, W. D., \& Ziauddin, M. (1998, August). Materialized views in Oracle. In VLDB (Vol. 98, pp. 2427).

Cavique, L., Cavique, M., \& Gonçalves, A. (2019, April). Extraction of fact tables from a relational database: an effort to establish rules in denormalization. In World Conference on Information Systems and Technologies (pp. 936-945). Springer, Cham.

Date, C. J. (2019). Denormalization. In Database Design and Relational Theory (pp. 161-182). Apress, Berkeley, CA.

Hay, M., Zhou, Y., Chen, Y., Friedman, M. A., \& Sahib, S. K. (2020). U.S. Patent Application No. 16/411,107.

Kanlı, İ. B., \& Kaplan, B. (2018). Kentsel Güvenliğin Sürdürülebilirliğinde İleri Teknolojilerin Kullanılması: Coğrafi Bilgi Sistemleri. TESAM Akademi, 143-186.

Karnitis, G., \& Arnicans, G. (2015, June). Migration of relational database to document-oriented database: Structure denormalization and data transformation. In 2015 7th International Conference on Computational Intelligence, Communication Systems and Networks (pp. 113-118). IEEE.

Li, G. (2010, December). Research of key technologies on encrypting vector spatial data in oracle spatial. In 2010 2nd International Conference on Information Engineering and Computer Science (pp. 1-4). IEEE.

Pogodaev, A., \& Ryzhkova, D. (2020, November). Developing Method to Optimize Queries in Denormalized Databases. In 2020 2nd International Conference on Control Systems,
Mathematical Modeling, Automation and Energy Efficiency (SUMMA) (pp. 687-691). IEEE.

Powell, G. (2006). Beginning database design. John Wiley \& Sons.

Shankar, K. R., \& Nagarajan, G. (2018). Automatic Denormalization of Databases.

Shekhar, S., Chawla, S., Ravada, S., Fetterer, A., Liu, X., \& Lu, C. T. (1999). Spatial databases-accomplishments and research needs. IEEE transactions on knowledge and data engineering, 11(1), 45-55.

Sheha, M. A., Sheha, A., \& Petilli, S. (2006). U.S. Patent No. 7,082,365. Washington, DC: U.S. Patent and Trademark Office.

Tasyurek, M., \& Celik, M. (2020). RNN-GWR: A geographically weighted regression approach for frequently updated data. Neurocomputing, 399, 258-270.

Taşyürek, M., \& Çelik, M. (2021). FastGTWR: Hızlı coğrafi ve zamansal ağırlıklı regresyon yaklaşımı. Gazi Üniversitesi Mühendislik Mimarlık Fakültesi Dergisi, 36 (2), 715-726. DOI: $10.17341 /$ gazimmfd.757131

Tecim, V. (2008). Coğrafi bilgi sistemleri: Harita tabanlı bilgi yönetimi. Vahap Tecim.

Uzun, E., Buluş, H. \& Erdoğan, C. (2018). Veritabanı Tasarımının Yazılım Performansına Etkisi: Normalizasyona karşı Denormalizasyon. Süleyman Demirel Üniversitesi Fen Bilimleri Enstitüsü Dergisi, 22 (2), 887-895.

Yu, T. F., Raitto, J., Panchapagesan, B., Lawande, S., \& Bello, R. G. (2011). U.S. Patent No. 7,930,297. Washington, DC: U.S. Patent and Trademark Office.

Zhang, Y., Wang, S., \& Lu, J. (2018). Fusion OLAP: Fusing the Pros of MOLAP and ROLAP Together for In-memory OLAP. IEEE Transactions on Knowledge and Data Engineering, 31(9), 1722-1735. 